\title{
The Role of Geoengineering in Field Development
}

\author{
Patrick W. M. Corbett
}

Additional information is available at the end of the chapter

http://dx.doi.org/10.5772/50535

\section{Introduction}

The oil and gas industry is truly multi-disciplinary when it comes to analysing, modelling and predicting likely movement of fluids in the subsurface reservoir environment. Much has been written on the subject of integration in recent years and in this Chapter we can consider one particular approach to tackling the problem. The Petroleum Geoengineering[1] solution is offered to the origin, understanding, and static geological modelling of a reservoir and the simulation of the flow and the dynamic response to a production test. In field development these models remain a key monitoring and planning tool but here we consider the initial modelling steps only. As an example of building a heterogeneous reservoir model, we have chosen to illustrate this approach for certain types of fluvial reservoirs [which have presented challenges for reservoir description for many years, 2,3] which can benefit further from this detailed integrated approach. Furthermore, as such reservoirs are characterised by relatively low oil recovery, and where further intensive work by the industry will be needed to maintain hydrocarbon supplies in the future.

Integration challenge. It is often quoted that the use of the word "Integration" in SPE paper titles has followed a 'hockey stick' rise in recent years. Books have been written on the subject of integration and in the forward to one such study - Luca Cosentino[4] pointed out that studies were merely becoming less disintegrated as the industry evolved. The industry has developed ever more powerful, cross-disciplinary software platforms and workflows to help integration. In parallel is the need for professionals to stay abreast of the key work processes in each discipline and this chapter helps illustrate one such integrated approach from a scientific/technological approach rather than embedded in or wedded to particular software.

Geoengineering concept. This concept was introduced [1] into petroleum industry to capture the spirit of the workflow being a seamless progression from geological conceptual 
understanding, through petrophysical description to a numerical model and prediction of a dynamic response. The Petroleum Geoengineering approach outlined here is a small component of an all encompassing "Intentional manipulation of the subsurface environment as practiced by the petroleum industry with global impact". The recovery of oil and gas and the management of $\mathrm{CO} 2$ being the ultimate outcome and target of this approach.

Static and dynamic reservoir characterisation. Reservoir Characterisation is defined as the numerical quantification of reservoirs for numerical simulation. The petroleum industry often refers to static and dynamic characterisation of the subsurface and many workers will have their own interpretation of the terms. In the context of this Chapter we describe the rocks statically when we keep to a numerical characterisation of the rock at initial boundary conditions and dynamic being the response to some perturbation of the system (with production as an example). There are other definitions of static and dynamic properties (properties that can be changed versus those that cannot) but the above are followed here. Permeability - which only occurs during an experiment in response to a perturbation is considered static when it is the initial permeability of the system prior to the experiment.

Field Development: Field Development plans are based on computer simulation models of the field. This models consisting of multi-million cells are built by geologists for simulation by engineers. The resolution of geological models is often higher than can be accommodated by the flow simulation (particularly when complex fluids are involved). There is usually a reduction of geological detailed as the cells are upscaled in order to reduce the number of cells for computational expediency. The fundamental challenge being considered here is how detailed should the original model be and with this upscaling how the key properties are preserved in the model. Models are built prior to reservoir development, updated during the development and on continued use through the planning any improved oil recovery strategies and remain the key field development tool up until field abandonment.

\section{Origin of reservoir heterogeneity}

Clastic reservoirs are those made up of particles of rock that are the accumulated products of erosion, transport and deposition (Fig.1). Broadly speaking these are usually sands and clays and these types of reservoirs contain a significant proportion of the world's reservoirs. Within the clastic reservoir family are those reservoirs resulting from deposition by rivers fluvial reservoirs. Fluvial reservoir types are very varied with braided and meandering being important end members. Depending on the slope, sediment supply, nature of the floodplain, rain fall and proximity to mountainous sediment sources, the resulting reservoir architecture will vary from low net:gross, meandering up to high net:gross, braided (Fig.2). This describes the macroscopic variation - but within the channel sand bodies are additional textural variations at various meso- and micro-scopic scales. Each of these scales will have a potential impact on the hydrocarbon recovery.

Role of texture in controlling reservoir properties. In sandstones, primary texture exerts a large influence of reservoir properties [5]. Primary texture is measured by grain size, grain shape, grain sorting, clay content, etc. Well sorted and rounded sands, in sandstone 
reservoirs, tend to have good porosity and high permeability. Fine grained sands of the same uniform shape and sorting will also have good porosity, but lower permeability. Poorly sorted sandstone with a variation in grain shape and size, will tend to have low porosity and permeability.

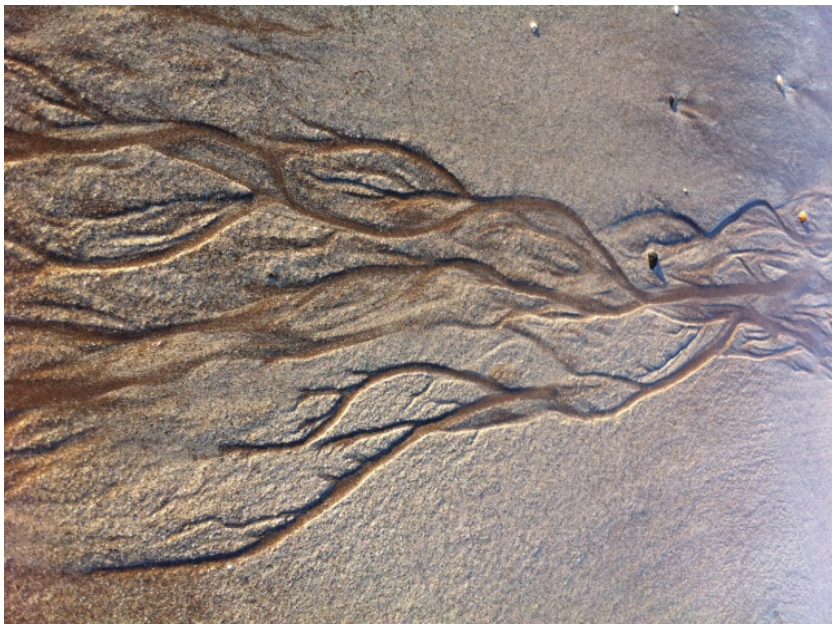

Figure 1. Modern analogue for a fluvial system showing characteristic channel channel complexity, Longcraigs Beach, Scotland
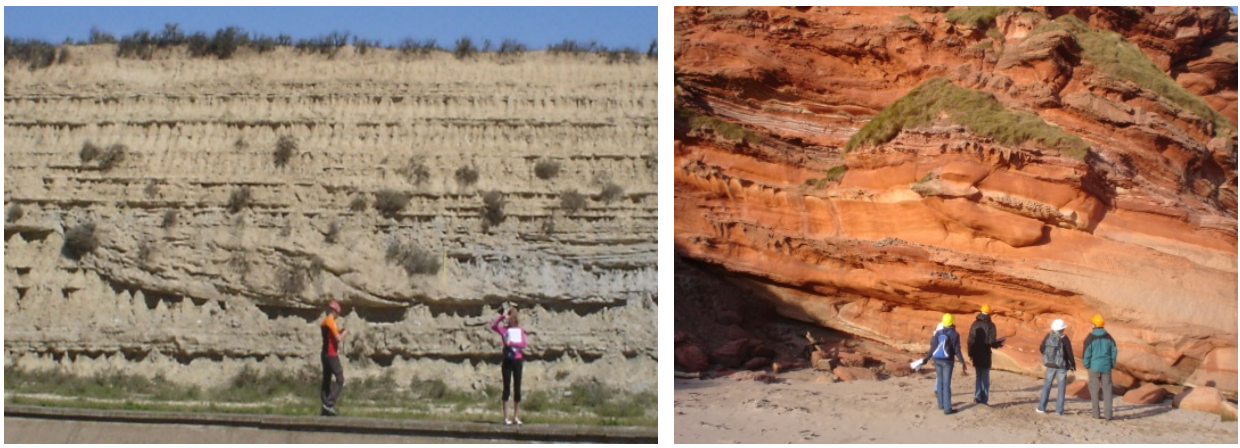

Figure 2. Various fluvial reservoirs at outcrop. Left low net:gross channelized, meandering, system from Tertiary, near Huesca, Spain. Right: High net:gross braided system from the Devonian, Scotland.

Where petrophysical heterogeneity in sandstones is present it is often due to the spatial distribution of these lithologies and their related properties which is why outcrop analogue studies remain a useful tool to define geobody geometries for reservoir modelling.

Use of Outcrop Analogues: The industry uses analogue reservoirs, outcropping on the surface, where relevant geological objects (geobodies) can be measured and their aspect ratios and stacking patterns determined (Fig. 3). Some very good outcrop analogues of fluvial reservoirs have been studies by the industry over the last 20 years [examples can be found 
over this period in 6,7] with outcrops in the UK (Yorkshire, Devon), Spain (S. Pyrenees) Portugal and the US (Utah) being used for reservoir studies in the North Sea, North Africa and Alaska. Geological age is not the critical consideration when it comes to chosing an analogue but net;gross (sand proportion in the system), channel size, bed load, flood plain, stacking patterns, climate, etc are more important criteria in selecting a 'good' outcrop analogue.

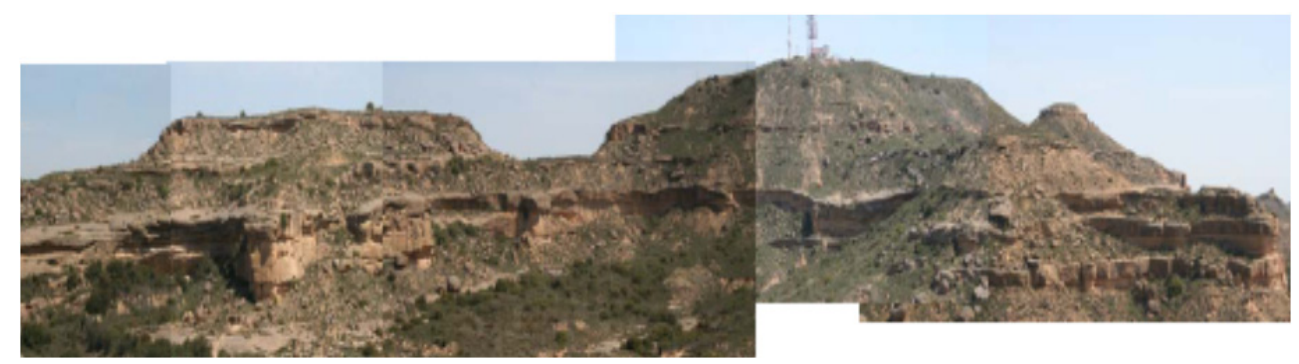

Figure 3. Outcrop of a fluvial system in Spain (near Huesca) where the average thickness of the channels was measured as 5.3m, with an average aspect ratio of 27:1 (with acknowledgement to the group of students who collected the data). Whilst only medium net:gross (35-45\%) the channels are laterally stacked and within these layers the connectivity will be greater than expected from a simple model with a random distribution of sandbodies).

\section{Measures of reservoir heterogeneity}

Heterogeneity usually refers to variation of a property above a certain threshold (so as to distinguish from homogeneity). In reservoirs, the property we usually consider, when referring to heterogeneity, is that which controls flow, namely permeability. Porosity, which controls the hydrocarbon in place, in the fluvial reservoirs we are considering in this Chapter, tends by contrast to be relatively homogeneous. Heterogeneity can be described by statistical criteria from a sample data set. The petroleum geoengineer's starting point is often an analysis of heterogeneity. This determines what level of detail might be required to characterise the flow process. Heterogeneity is sometimes responsible for anisotropy - but not always - so we have also to consider this aspect of the reservoir's characteristics.

Porosity and permeability distributions. Heterogeneity is often first seen in a review of the histograms of the porosity and permeability data and these should always be part of an initial reservoir analysis.

Porosity data tends to form a symmetrical or normal distribution. Permeability on the other hand is often positively skewed, bimodal and usually highly variable (Fig. 4) [8]. It is a mistake to think of permeability as being always log-normally distributed (as is often implied in the literature) and the type of distribution should always be checked. Sometimes the distributions are clearly bi- (tri- or even multi-) modal and this aspect will require further analysis. Ideally each important element of the reservoir should be described by characteristic porosity and permeability distributions - and these can be used in the geological (i.e., geostatistical) modelling. Geostatistical (i.e., pixel) modelling is often performed in a Gaussian domain (Sequential Gaussian Simulation) and the skewed distributions are first transformed to Gaussian to make this technique most effective. 


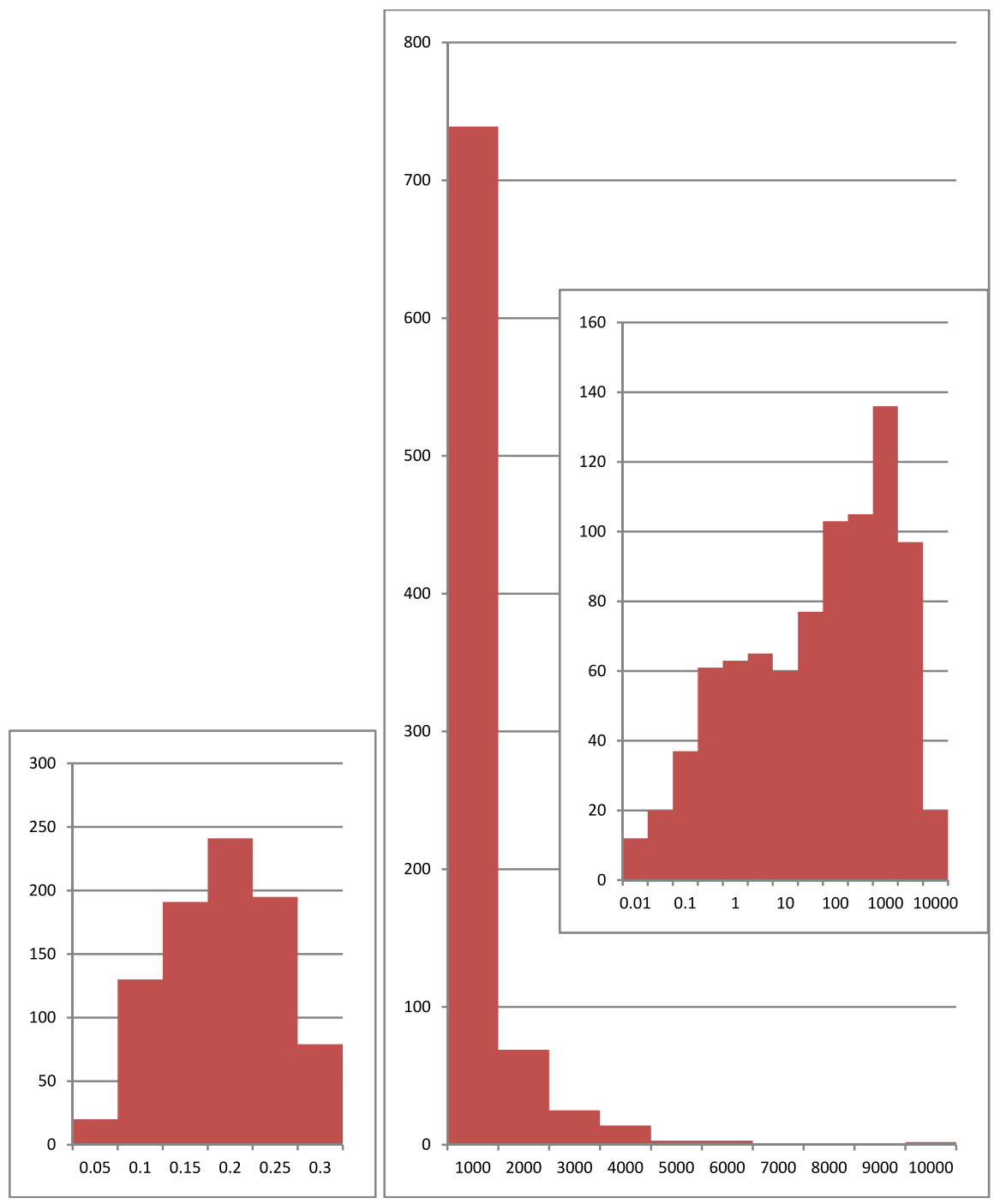

Figure 4. Porosity (Left - decimal), Permeability (Centre-mD) and Log Permeability (Right - mD) distributions for a fluvial data set. Porosity tends to a normal distribution with permeability being bimodal in the log domain (often this relates to properties of flood plain and channels)

Variation between Averages. Another useful indication of heterogeneity is apparent in differences between the arithmetic, geometric and harmonic averages (Table 1). For porosity these are often quite similar - but for permeability these can differ in fluvial reservoirs by orders of magnitude! Different averages have different applications in reservoir engineering and often used as a way of upscaling the directional flow properties (in the static model) in different directions. 


\begin{tabular}{|c|c|c|c|c|}
\hline & \multicolumn{2}{|c|}{ UK } & \multicolumn{2}{c|}{ North Africa } \\
\hline Average & Poro & Perm & Poro & Perm \\
\hline Arithmetic & 0.167 & 441 & 0.108 & 25.7 \\
\hline Geometric & 0.154 & 23.7 & 0.094 & 2.78 \\
\hline Harmonic & 0.138 & 0.263 & 0.072 & 0.009 \\
\hline
\end{tabular}

Table 1. Porosity (decimal) and permeability $(\mathrm{mD})$ averages in fluvial sandstones - Left Triassic Sherwood Sandstone, UK (Fig.4); Right Triassic Nubian Sandstone, North Africa. Note relatively small differences between average porosity contrasting with order of magnitude variation between average permeabilities. This is further evidence of extreme permeability heterogeneity in these sandstones.

The arithmetic average is used as an estimator of horizontal permeability, and the harmonic for the vertical permeability, in horizontally layered systems. Where layered systems have different orientations (i.e., significant dip) then the averages need to be 'rotated' accordingly.

In the case of a random system, then the geometrical average is used in both horizontal and vertical directions. A truly random system, without any dominant directional structure, can also be assumed to be isotropic. Use of theses averages for upscaling comes with some caveats - the assumption that each data point carries the same weight (i.e., from a layer of the same thickness) and only single phase flow is being considered. In many fluvial reservoirs, the system is neither nicely layered nor truly random which requires careful treatment/use of the averages.

Coefficient of Variation $\left(\mathbf{C}_{\mathrm{v}}\right)$. There are a number of statistical measures which are used in reservoir engineering to quantify the heterogeneity. The variance and the standard deviation are the well known ones used by all statisticians. However, in reservoir characterisation we tend to use the normalised standard deviation (standard deviation divided by the arithmetic average) as one such measure of heterogeneity and this is known as the Coefficient of Variation (Table 2) [8]. Another measure of heterogeneity, that probably has limited use to petroleum engineering only, is the Dykstra-Parsons coefficient (VDP), but this assumes a log-normal distribution (of permeability) so tends to be used in modelling studies when a log-normal distribution is required to be input to the simulation process. The log-normal distribution, as discussed above, is not always found to be the case for permeability in reservoir rocks and therefore care has to be taken when using VDP.

\begin{tabular}{|c|c|c|c|c|}
\hline & \multicolumn{2}{|c|}{ UK } & \multicolumn{2}{c|}{ North Africa } \\
\hline & Poro & Perm & Poro & Perm \\
\hline S.D. & 0.061 & 972 & 0.046 & 58.9 \\
\hline C $_{\mathrm{v}}$ & 0.37 & 2.20 & 0.425 & 2.29 \\
\hline
\end{tabular}

Table 2. Heterogeneity in porosity (decimal) and permeability $(\mathrm{mD})$ averages in fluvial sandstones Left Triassic Sherwood Sandstone, UK (Fig. 4); Right Triassic Nubian Sandstone, North Africa. Note porosity heterogeneity is low (but relatively high for sandstones) whereas permeability is very heterogeneous supporting the trend seen in the averages. Note these two Triassic reservoirs on different continents have remarkably consistent poroperm variability. 
Lorenz Plot (LP): The Lorenz Plot (which is more widely known in economics as the GINI plot) is a specialised reservoir characterisation plot that shows the relative distributions of porosity and permeability in an ordered sequence (of high-to-low rock quality, essentially determined by the permeability, Fig. 5 right) and can be quantified - through the Lorenz Coefficient. Studying how porosity and permeability jointly vary is important. In Fig. 5 (left) $80 \%$ of the flow capacity (transmissivity) comes from just $30 \%$ of the storage capacity (storativity).
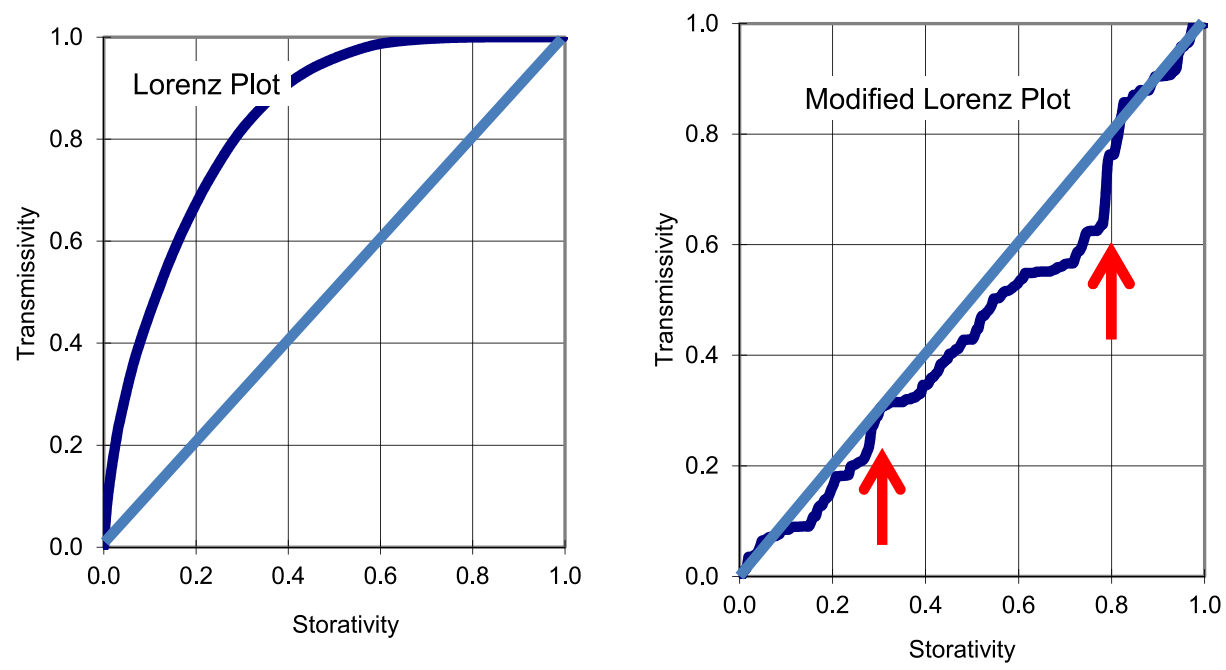

Figure 5. Example Lorenz and Modified Lorenz Plots for a fluvial data set (Fig.4). The LP (Right) shows high heterogeneity as the departure of the curve from the $45^{\circ}$ line. The MLP (Left) shows presence of speed zones at various point (arrowed) in the reservoir. If the MLP is close to the $45^{\circ}$ line then that is perhaps an indication of randomness and this can also be checked by variography.

The industry often uses cross plots of porosity and permeability - which will be discussed further below - which can focus the viewer on average porosity permeability relationships but the LP should appear in every reservoir characterisation study as it emphasises the extremes that so often identify potential flow problems.

Modified Lorenz Plot (MLP). In a useful modification of the original Lorenz Plot where the re-ordering of the cumulative plot by original location provides the locations of the extremes (baffles and thief or speed zones). This plot (Fig. 5 left) has a similar profile to the production log and hence is an excellent tool for predicting inflow performance. The LP and MLP used in tandem can provide useful insights in to the longer term reservoir sweep efficiency and oil recovery.

Anisotropy vs Heterogeneity. With heterogeneity, sometimes comes anisotropy, particularly if the heterogeneity shows significant correlation structure. Correlation is 
measured by variography and where correlation lengths are different in different directions - this can identify anisotropy. Correlation in sedimentary rocks is often much longer in the horizontal and this gives rise to typical $\mathrm{kv} / \mathrm{kh}$ anisotropy. In fluvial reservoirs, with common cross-bedding, the anisotropy often relates to small scale structure caused by the lamination but it is the larger scale connectivity that dominates (see the Exercise 1 in reference [1] for further consideration of this issue).

Rarely does significant anisotropy result from grain anisotropy alone as has been suggested by some authors. Anisotropy is a scale dependent property - smaller volumes tend to be isotropic (and this tendency is seen in core plugs) whereas at the formation scale bedding fabric tends to give more difference between $\mathrm{kv}$ and $\mathrm{kh}$ and therefore greater anisotropy. In fluvial systems, the arrangement of channel and inter-channel elements can have a significant effect on anisotropy. In high net:gross fluvial systems, well-intercalated channel systems will have higher tendency to be isotropic (geometric average) whilst preservation of more discrete channels will exhibit more anisotropic behaviour (arithmetic and harmonic average permeability). In this Chapter we are not considering natural or induced fractures which can increase anisotropy.

\section{Reservoir rock typing}

Petrophysicists use the term "Rock Typing" in a very specific sense - to describe rock elements (core plugs) with consistent porosity - permeability (i.e., constant pore size - pore throat) relationships. These relationships are demonstrated by clear lines on a poro-perm cross-plot and similar capillary pressure height functions. There are various ways these relationships can be captured (and the literature includes references to RQI, FZI, Amaefule, Pore radius, Winland, Lucia, RRT, GHE, Shenawi....) and each method directs the petrophysicist towards a consistent petrophysical sub-division of the reservoir interval. In Fig. 6 the coloured bands follow a consistent GHE approach based on the Amaefule FZI, RQI equation [9]. It matters not so much which rock typing method is used but that a rock typing method is used but that a rock typing method is used as the basis for reservoir description. Geologists and petrophyicists need to make these links work for an effective reservoir evaluation project. Special core analysis data when collected in a rock typing framework is most useful.

Property variation in poro-perm space. In fluvial reservoirs, it is very common to have a wide diversion of porosity and permeability (Fig. 6) due to the poorly sorted, immature, nature of these sands. Well sorted sands will have higher porosity and permeability than their poorly sorted neighbours. Coarse sands tend to have less primary clay content. Presence of mica and feldspar can also effect the textural properties - especially if the feldspar breaks down into clay components. Clays are more common in fine and poorly sorted sandstones. The variation of properties within fluvial systems is often a result of primary depositional texture. Diagenetic effects - especially where associated with calcrete (carbonate cement that is formed by surface evaporation and plant root influence 
in arid fluvial environments) or reworked calcrete into channel base (lag) deposits - can modify the original depositionally-derived properties (such as well cemented lag intervals) but perhaps do not change the overall permeability patterns. For this reason channel elements are often detected in fluvial reservoirs and are measured at outcrop for use in fluvial reservoir modelling studies.
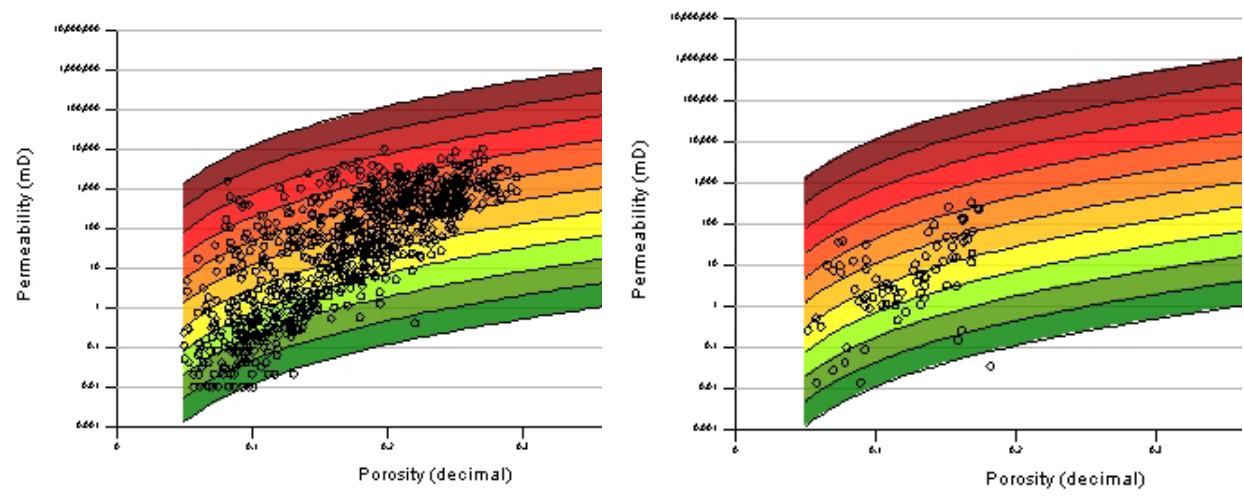

Figure 6. Porosity and permeability heterogeneity in fluvial sandstones - Left Triassic Sherwood Sandstone, UK; Right Triassic Nubian Sandstone, North Africa.

Link between geology and engineering. Rock types are a key link between geology and engineering as they are the geoengineering link between the depositional texture, the oil in place and the ease with which water can imbibe and displace oil. If fluvial reservoirs the presence of many rock types is critical to understanding oil-in-place and the, relatively low, recovery factors. Rock types are the fundamental unit of petrophysical measurement in a reservoir and failure to recognise the range of properties in a systematic framework can potentially result in the use of inappropriate average properties.

Link between MLP and rock typing. The MLP if coded by rock type can also emphasise the role of some rock types as conduits to flow and potential barriers/baffles to flow [10]. The link between rock types and heterogeneity is also important in understanding the "plumbing" in the reservoir - where are the drains, the speed zones, the thief zones, the baffles and the storage tanks?

Production logging. Ultimately the proof of what flows and what doesn't flow in a reservoir comes with the production (i.e, spinner) log. The spinner tool identifies flowing and nonflowing intervals (by the varying speed of rotation of a impellor in the well stream) and when correlated with the MLP can provide validation that the static and dynamic model are consistent [11]. If the best, and only the best, rock types are seen to be flowing then there is evidence of a double matrix porosity reservoir. If there is no correlation, then perhaps this points to evidence of a fractured (double porosity) system. The well test interpretation cannot distinguish between the two double porosity cases - but the production log perhaps 
can. Of course when it comes to interpreting downwhole data - there are also the downhole environment considerations needed (such as perforation location, perforation efficiency, water or gas influx, etc) to be taken into account. The geoengineering approach to calibrating a static model with a dynamic model for key wells (where there is perhaps core, $\log$, production log and test data) and iterating until there's a match will have benefits when it comes to subsequent history matching of field performance.

Core to Vertical Interference Test comparison $\left(\mathbf{k}_{\mathbf{v}} / \mathbf{k}_{\mathbf{h}}\right)$. Where there is also vertical interference data available, which is generally quite rarely, this can also be used to calibrate models of anisotropy [12]. The $\mathrm{k}_{\mathrm{v}} / \mathrm{kh}_{\mathrm{h}}$ ratio is often one of the critical reservoir performance parameters but rarely is there a comprehensive set of measurements. Core plug scale $\mathrm{k}_{\mathrm{v}} / \mathrm{kh}_{\mathrm{h}}$ measurements are not always helpful - as they are often 'contaminated' by local heterogeneity issues at that scale. Vertical plugs are often sampled at different always wider - spacings, compared with horizontal plugs, and this means critical elements (which tend to be thin) controlling the effective vertical permeability are often missed. In fluvial reservoirs, these are often the overbank or abandonment shale intervals. Vertical plug measurements in shales are often avoided for pragmatic reasons (because measuring low permeability takes time and often the material doesn't lend itself to easy plugging). The effective $\mathrm{k}_{\mathrm{v}} / \mathrm{k}_{\mathrm{h}}$ parameter that is needed for reservoir performance prediction often needs to be an upscaled measurement. Choosing the interval over which to conduct a representative vertical interference test is an important consideration if that route is chosen.

\section{Dynamic well testing}

Well testing is achieved by perforating, producing and shutting-in the well for a relatively short period of time, whilst recording the flow rates and (bottom-hole as the estimate of reservoir) pressures. The practical aspects are covered elsewhere in this book, here we consider the role of well test data in understanding the performance of fluvial reservoirs. The way that fluid flows towards the well bore following a perforating job, and the paths that the pressure drop takes in the reservoir are important considerations. Fluvial reservoirs are not homogeneous, isotropic, sands of constant thickness. They are systems with highly variable (showing many orders of magnitude permeability variation for the same porosity) internal properties. The paths (comprising both horizontal and vertical components) of pressure disturbance away from the well will depend very much on the 3D arrangement of the sand bodies and the floodplain characteristics - the reservoir plumbing (Fig.7) [13]. In this respect, fluvial reservoirs are some of the more complex (clastic) reservoirs encountered.

The diffusion of the pressure response into the reservoir is constrained by the diffusivity constant. In heterogeneous formations such as fluvial reservoirs this assumed constant isn't actually constant and varies with rock quality through the tested volume. In an ideal case the arithmetic average would be expected in the initial period of the test and the geometric 
at later stages (for a completely random system (Fig. 8). In reality, there are a number of less than ideal situations in the geology. Channels are not always big enough to see the first stabilisation clearly and the system is not absolutely random and therefore the geometric average is not always reached in the length of the test. These problems give rise to many well test interpretation challenges in fluvial reservoirs.

Cross-flow and comingled flow. When a reservoir is said to have cross-flow this means that the fluid passes in response to pressure changes between layers of different properties in the reservoir. This effect occurs in all directions - vertically and laterally - rather than in simple uniform radial directions from the well.
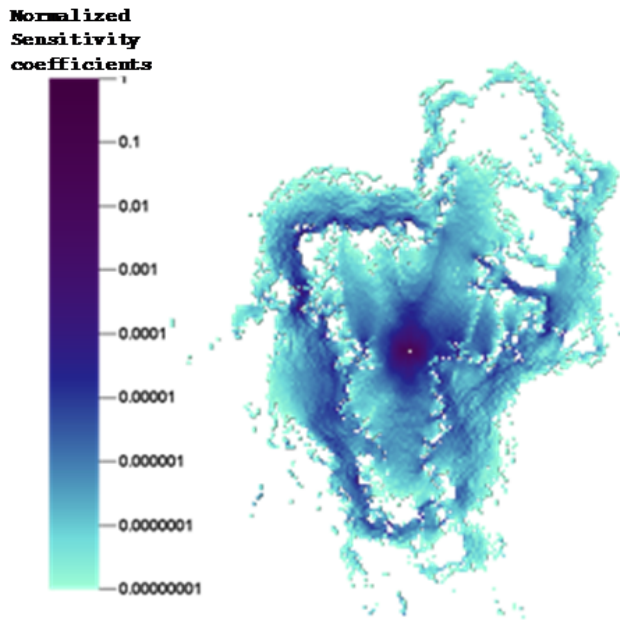

Figure 7. A simulation showing the location of the most sensitive parts of the formation at a particular time to the pressure response measured at the well. This effectively illustrates complex pressure diffusion (rather than simple radial flow) in a fluvial reservoir [13].

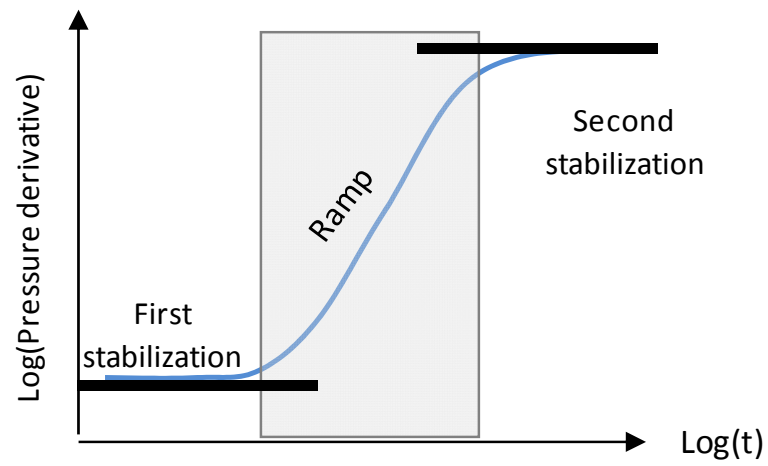

Figure 8. An ideal pressure derivative showing two stabilisations - the first would be expected to give the arithmetic average and the second, the geometric average. Remember that the difference between the arithmetic and geometric average in fluvial reservoirs is an order of magnitude or more (Table 1). 
In a commingled reservoir the reservoir layers only communicate through the well bore. In the reservoir there is not flow between the layers. This situation is much more common in more layered reservoirs with laterally extensive shales between sheet-like (e.g. turbidite) sand bodies. Such situations can occur in fluvial systems - ephemeral channel sands sandwiching sheetflood deposits and interbedded shales - but perhaps as an exception, rather than the rule.

High net:gross fluvial reservoirs are often cross-flow in their internal drainage nature and cross-flow reservoirs are recognised as the most challenging for enhanced oil recovery. Gravity means that water slumps - or gas overrides - more easily in cross flow reservoirs. Shutting-off water influx - or gas - in producing well is ineffective as there are no laterallyextensive reservoir barriers present to base this strategy upon.

In homogeneous formations. Where the heterogeneity is low ( $C_{v}$ less than 0.5), the effects of cross flow are mitigated. Low heterogeneity fluvial sands can occur where the sands are relatively mature and far from source. This tends to occur in more distal locations. In these locations wind-blown sands can also occur and these are usually more uniform. In these situations well test will see the arithmetic (equals geometric) average permeability.

In heterogeneous formations. Where the heterogeneity is moderate $\left(C_{v}\right.$ between 0.5 and 1.0) these reservoirs might be dominated by cross bedding (not identified in low more homogeneous reservoirs) and these will induce strong capillary trapping. The well test might show reduced geometric average permeability in this case. Square root of $\mathrm{k}_{x}$ and $\mathrm{k}_{\mathrm{y}}$ product for significant lateral (point bar) or downstream accretion-derived anisotropy.

In highly heterogeneous formations. Where the heterogeneity is very high $\left(\mathrm{C}_{\mathrm{v}}\right.$ greater than 1.0) and often this is the case with braided fluvial reservoirs then the most extreme cross flow can be seen. These are often detected by speed zones, drains) in the production log profile. Cross-flow introduces flow regime which can be confused with parallel (i.e. channel) boundaries. The ramp is seen best when the vertical permeability is effectively zero and the second stabilisation converges at the harmonic average within the commingled layers (Fig. 9 lower). The geometric average is seen when there is good connectivity and any channels near the well give rise to a geoskin response (Fig. 9 - top). In the middle case the restriction cause by the limits of the channels near the well is overcome in the later time by increased connectivity and this is the geochoke response (Fig. 9 - middle). These responses can be confused with the effects of faults (which may also be present and add to the confusion!).

Reservoir boundaries. The detection of reservoir boundaries is an important aspect of the well test interpretation. In relatively uniform sand properties then boundaries might be readily detected. In highly heterogeneous reservoirs cross flow effects might be misinterpreted as faults. It is often commented that well tests in fluvial reservoirs tend to 
show faults short (ca. 40ft) from the well. These may be channel margins or perhaps more likely, subtle, cross flow effects. The degree of heterogeneity is an important consideration in deducing boundaries (either sedimentological or structural) from internal cross flow effects. The impact of the two interpretations on the approach taken to reservoir modelling will be significant.

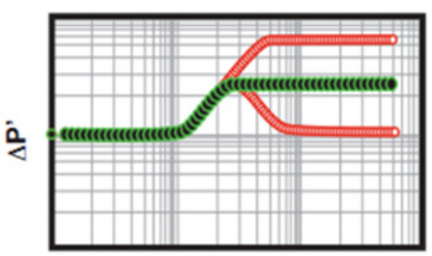

Time, hr

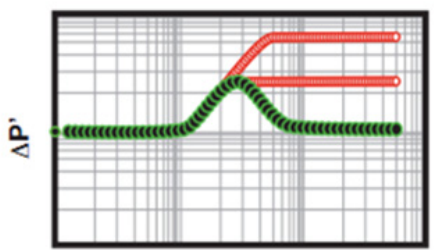

Time, hr

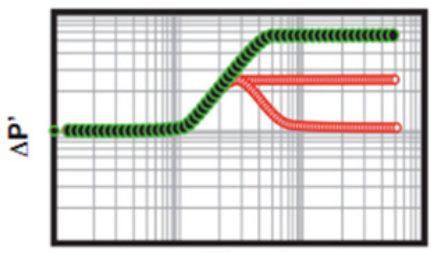

Time, hr
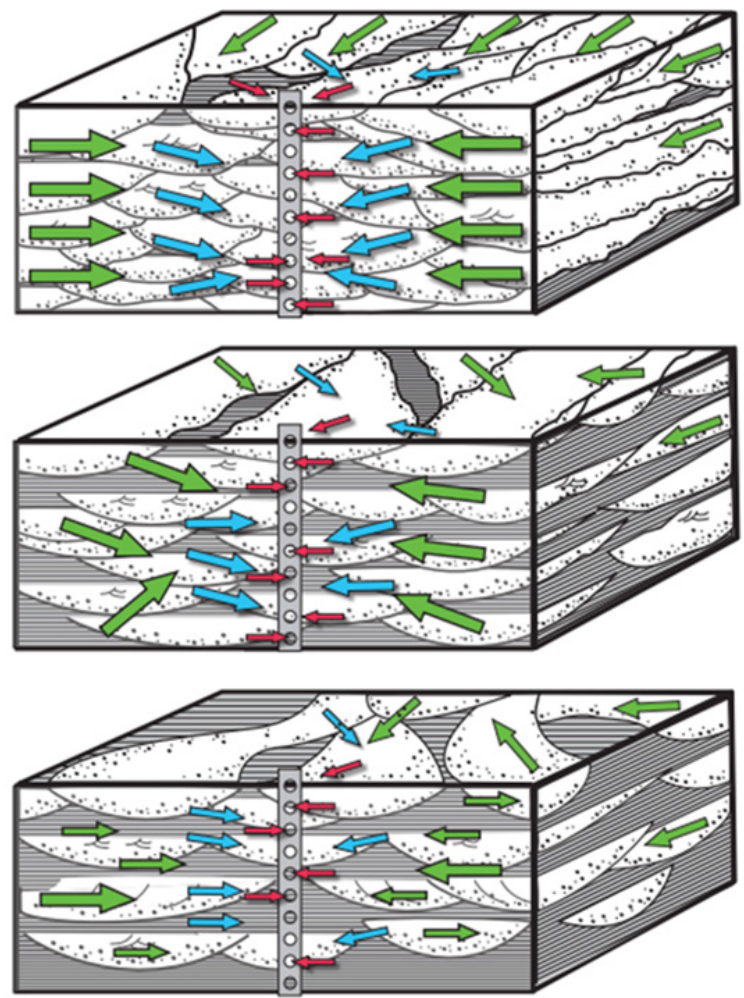

Figure 9. Shows various connectivity arrangements in fluvial reservoirs (between channels and floodplain) and an equivalent schematic pressure deriviative responses to the scenarios [13]. With subtle changes in lateral and vertical connectivity the response changes from a geoskin response (top) to a geochoke response (middle) or to a ramp response (lower).

Reservoir limit tests. Fluvial systems to produced sand bodies that are limited in extent (point bars). These are characterised but unit slope depletion on the well test response [14]. Point bars are often of a particular geometry (ca 3 times as long as wide) in which linear flow will not develop. From depletion, reservoir volumes can be determined - and these 
will be small if detected during a short (i.e. 24hr) production test. There are relationships published between thickness, width and volume - for point bar sandstones. Of course, in some fluvial reservoirs a mixture of channel body boundaries and fault induced boundaries may be present.

\section{Considering other very heterogeneous reservoirs - Carbonate and fractured}

A few words are warranted of other even more heterogeneous reservoirs - where aspects of the above will be important to note and the effects may be even more dramatic.

Very high heterogeneity. Carbonates often have even larger ranges of permeability for given porosity and this will translate into even higher measures of variability. Sometimes the presence of vugs are not captured in the core plug data - because of their size. This effect is mitigated by the use of whole core samples - but these are also of limited use where very large vugs are present.

Multiple rock types. Carbonates have many more reservoir pore space creation mechanisms - often diagenetic by origin - which adds to the complexity. Dissolution, vugs, stylolites, microporosity, dolomitisation are just a few of the additional geological phenomena/processes, that impact reservoir properties, to look out for in carbonates.

Fractures. Carbonate (and occasionally fluvial) reservoirs are often fractured. Detecting fractures relies on core, image logs and production logs - being carful not to confuse fractures with high permeability matrix elements as discussed above, does require special attention. Fractures are rarely sampled in core plugs - but where they are often stand out as high permeability, low porosity anomalies.

Well testing considerations. Identification of fractures and boundaries - natural or artificial - from highly heterogeneous reservoirs might be misleading. Complex double matrix porosity considerations with lateral and vertical cross flow effects might be confused with double porosity interpretations. Negative skin is not necessarily a diagnostic signature of a fractured reservoir. Geoskin can result from presence of high-permeability 'pseudochannels' which are present in make fluvial reservoirs.

\section{Effect of heterogeneity on oil recovery}

Poor areal and vertical sweep leads to poor oil recovery from a reservoir [15]. Fluvial reservoirs with disconnected channels or partially- and variably-connected, vertical and laterally aggrading sand bodies (the net: gross and the lateral and vertical architectural stacking patterns are critical in this respect) will have very variable flow paths through the system. Rarely will the sweep be uniform -more likely to be fingering, bypassing and dispersive - leading to high remaining mobile oil $[16,1]$. Cross-flow is a problem for gas and water flooding as there is little to counteract the effects of gravity and the is often the reason why WAG works well in high net:gross fluvial reservoirs. 
Low net to gross fluvial reservoirs require something very different as connectivity is the major challenge and infill drilling may be the answer. Where there is good sand continuity the presence of cross-bedding might impact the capillary trapping of remaining oil.

There is no doubt that fluvial reservoirs are complex and that finding the right engineering solution will be a painstaking and demanding task. Gravity and capillary forces in the reservoir and the viscous-dominated issues in the connectivity of the reservoir to the producing wells have all to be overcome.

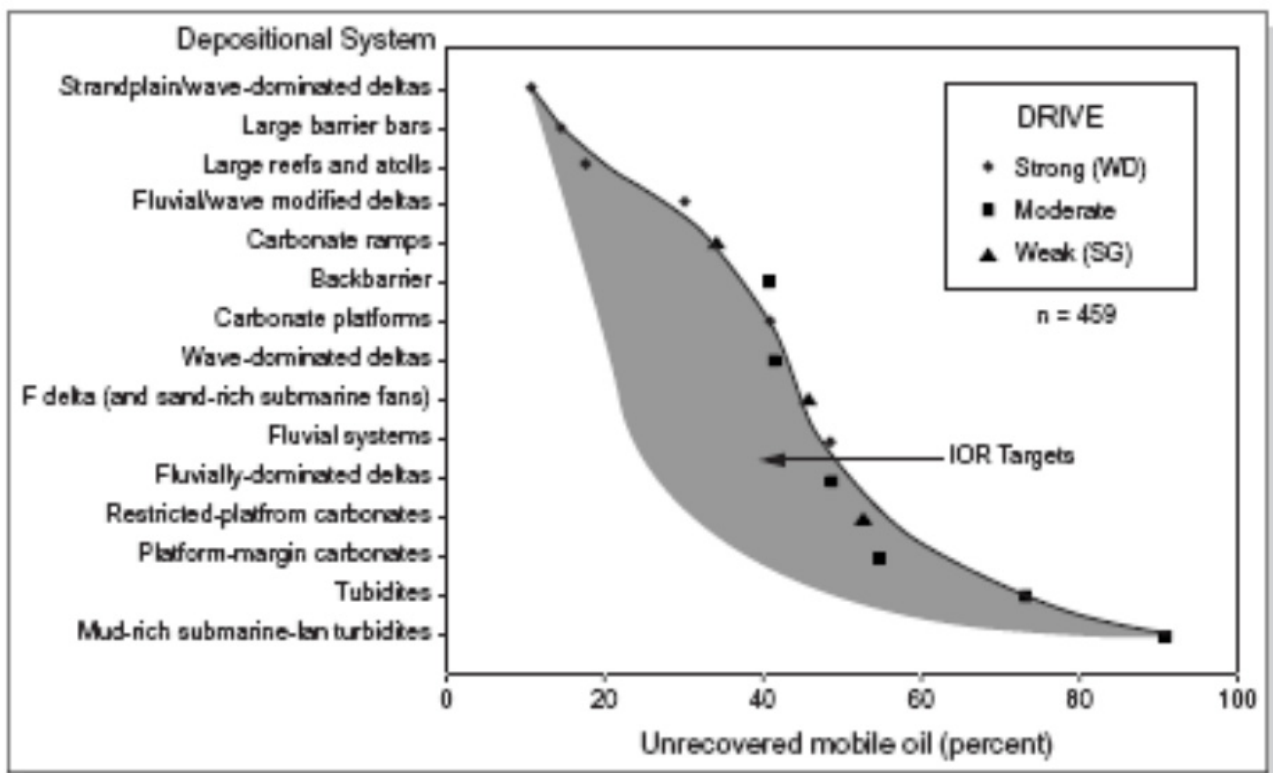

Figure 10. Potential IOR targets in fluvial systems where high amounts of unrecovered oil remain [from 16 and adapted in 1]. A better understanding of the connectivity issues and potential habitat of the unrecovered oil in fluvial reservoirs is a multidisciplinary, geoengineering challenge.

\section{Conclusions}

All petroleum reservoirs are certainly not of fluvial origin. However, fluvial reservoirs are good reservoirs in which to study the impact of reservoir and that's why I chose them to illustrate this chapter. The reader will have to extrapolate their learnings to other reservoir systems. Fluvial reservoirs are also good reservoirs in which to demonstrate, and to understand the relevance of, close integration between the disciplines. Their understanding and development benefits from such a close integration of geoscience and engineering 
technology. Through gaining this understanding the reader and industry will doubtless develop improved performance capabilities and thereby engineer higher recovery in these (and other such complex) systems.

\section{Author details}

Patrick W. M. Corbett

Institute of Petroleum Engineering, Heriot-Watt University, Edinburgh, UK

Institute of Geosciences, Universidade Federal do Rio de Janeiro, Brazil

\section{Acknowledgement}

The author acknowledges the contributions by many students over the years to his understanding and many of those are co-authors in the references. Patrick also acknowledges 17 years of funding from Elf and Total over which period the work on fluvial reservoirs was a major effort.

\section{Symbols}

FZI Flow Zone Indicator

GHE Global Hydraulic Elements

IOR Improved Oil Recovery

$\mathrm{k}_{\mathrm{v}} \quad$ Vertical permeability

$\mathrm{kh}_{\mathrm{h}} \quad$ Horizontal Permeability

$\mathrm{k}_{\mathrm{x}, \mathrm{k}} \quad$ Permeability in orthogonal horizontal directions

LP Lorenz Plot

$\mathrm{mD} \quad$ Milledarcy

MLP Modified Lorenz Plot

RQI Reservoir Quality Index

RRT Reservoir Rock Type

S.D. Standard Deviation

SG Solution Gas Drive Mechanism

VDP Dykstra-Parsons Coefficient

WAG Water Alternating Gas

WD Water Drive Mechanism

\section{References}

[1] Corbett, P.W.M., 2009, Petroleum Geoengineering: Integration of Static and Dynamic Models, SEG/EAGE Distinguished Instructor Series, 12, SEG, 100p. ISBN 978-1-56080153-5 
[2] Davies, D. K., Williams, B. P. J. \& Vessell, R. K.: “Models for meandering and braided fluvial reservoirs with examples from the Travis Peak Formation, East Texas", SPE 24692, 1992.

[3] Corbett, P.W.M., Zheng, S.Y., Pinisetti, M., Mesmari, A., and Stewart, G., 1998; The integration of geology and well testing for improved fluvial reservoir characterisation, SPE 48880, presented at SPE International Conference and Exhibition, Bejing, China, 2-6 Nov

[4] Cosentino, L., 2001, Integrated Reservoir Studies, Editions Technip, Paris, 310p.

[5] Brayshaw, A.C., Davies, R., and Corbett, P.W.M., 1996, Depositional controls on primary permeability and porosity at the bedform scale in fluvial reservoir sandstones, Advances in fluvial dynamics and stratigraphy, P.A.Carling and M. Dawson (Eds.), John Wiley and Sons, Chichester, 373-394.

[6] Flint, S.S., and Bryant, I.D., 1993, Geological Modelling of Hydrocarbon Reservoirs and Outcrop Analogues, International Association of Sedimentologists, Wiley, ISBN 9780632033928, Online ISBN 9781444303957

[7] CIPR, University of Bergen, Norway, accessed 19May 2012, http://www.cipr.uni.no/projects.aspx?projecttype $=12 \&$ project $=86$

[8] Corbett, P.W.M., and Jensen, J.L., 1992. Estimating the mean permeability: How many measurements do you need? First Break, 10, p89-94

[9] Corbett, P.W.M., and Mousa, N., 2010, Petrotype-based sampling to improved understanding of the variation of Saturation Exponent, Nubian Sandstone Formation, Sirt Basin, Libya, Petrophysics, 51 (4), 264-270

[10] Ellabad, Y., Corbett, P.W.M., and Straub,R., 2001, Hydraulic Units approach conditioned by well testing for better permeability modelling in a North Africa oil field, SCA2001-50, Murrayfield, 17-19 September, 2001.

[11] Corbett, P.W.M., Ellabad, Y., Egert, K., and Zheng, S.Y., 2005, The geochoke test response in a catalogue of systematic geotype well test responses, SPE 93992, presented at Europec, Madrid, June

[12] Morton, K., Thomas, S., Corbett, P.W.M., and Davies, D., 2002, Detailed analysis of probe permeameter and vertical interference test permeability measurements in a heterogeneous reservoir, Petroleum Geoscience, 8, 209-216.

[13] Corbett, P.W.M.,Hamdi, H.,and Gurev, H., 2012, Layered Reservoirs with Internal Crossflow: A Well-Connected Family of Well-Test Pressure Transient Responses, Petroleum Geoscience, v18, 219-229.

[14] De Rooij, M., Corbett, P.W.M., and Barens, L., 2002, Point Bar geometry, connectivity and well test signatures, First Break, 20, 755-763

[15] Arnold, R., Burnett, D.B., Elphick, J., Freeley III, T.J., Galbrun, M., Hightower, M., Jiang, Z., Khan, M., Lavery, M., Luffey, F., Verbeek, P., 2004, Managing Water - From waste to resource, The Technical Review, Schlumberger, v16, no2, 26-41 
[16] Tyler, N., and Finley, R.J., 1991, Architectural controls on the recovery of hydrocarbons from sandstone reservoirs, in Miall, A.D., and Tyler, N., (eds.) The three dimensional facies architecture of terrigeneous clastic sediments and its implications for hydrocarbon discovery and recovery, SEPM Concepts in Sedimentology and palaeontology, Tulsa, Ok, 3, 1-5 